\title{
Nickel-catalyzed aryl trifluoromethyl sulfides synthesis: A DFT study
}

Received 00th January 20xx, Accepted 00th January 20xx DOI: $10.1039 / \times 0 \times x 00000 x$

\author{
Jesús Jover ${ }^{\mathrm{a} *}$
}

\begin{abstract}
The Ni-catalyzed trifluoromethylthiolation of aryl halides with $\left[\mathrm{NMe}_{4}\right]\left[\mathrm{SCF}_{3}\right]$ has been studied with DFT methodology to find out the mechanism governing the reaction. Two different cross-coupling pathways have been explored; the first one, involving the classical $\mathrm{Ni}(0) / \mathrm{Ni}(\mathrm{II})$ catalytic cycle, does not provide a good explanation for the experimental outcomes. In contrast, an alternative $\mathrm{Ni}(\mathrm{I}) / \mathrm{Ni}(\mathrm{III})$ catalytic cycle affords a much better agreement with what is observed experimentally: a low reaction barrier that allows the reaction to work at room temperature for aryl iodides, and an interpretation of the reactivity for other aryl halides and substituted iodobenzenes. The active $\mathrm{Ni}(\mathrm{I})$ catalyst is generated through a two-step process consisting of a singlet to triplet transformation of the initial nickel species followed by a subsequent halogen atom transfer from the aryl halide.
\end{abstract}

\section{Introduction}

The $\mathrm{SCF}_{3}$ group has become one of the most important motifs in the development of new agrochemical and pharmaceutical candidates. The large Hansch constant $(\pi=1.44)^{1}$ of this substituent enhances the ability of molecules to cross lipid membranes and thus increases the possibility of biological absorption. In fact, several bioactive compounds such as fungicide, herbicide, antimalarial, antiarthritic, hypotensive and nervous anorexia treatment agents containing the $\mathrm{SCF}_{3}$ group have been developed in recent years ${ }^{2}$ (Scheme 1 ).<smiles>[R]n1c(=O)sc2ccc(C(=O)NCc3ccc4c(c3)[AsH](F)(F)C4)cc2c1=O</smiles><smiles>[R]OC(=O)Nc1c([N+](=O)[O-])cc(S(F)(F)F)cc1[N+](=O)[O-]</smiles><smiles>CCNC(CO[Mg]O)Cc1cccc(C(F)(F)F)c1</smiles><smiles>CCCCCc1nc2cc(C(F)(F)F)ccc2n1Cc1ccc(-c2ccccc2-c2nnn[nH]2)cc1</smiles><smiles>OC1OC(C[As](F)(F)F)C(O)C1O</smiles>

$$
\text { Antimalarial }
$$$$
\text { treatment }
$$

Scheme 1. Bioactive compounds containing the trifluoromethylsulfide $\left(\mathrm{SCF}_{3}\right)$ group.

A number of different methods have been applied to

\footnotetext{
a. Departament de Química Inorgànica i Orgànica, Secció de Química Inorgànica and Institut de Química Teòrica i Computacional (IQTC-UB), Universitat de Barcelona, Martí i Franquès 1-11, 08028 Barcelona, Spain.

Electronic Supplementary Information (ESI) available: Computed Gibbs energy values, SET energies and components, and optimized geometries in cartesian (xyz) coordinates. See DOI: 10.1039/x0xx00000x
}

synthesize trifluoromethylthiolated molecules from convenient $\mathrm{SCF}_{3}$ sources and a wide variety of precursors and catalysts have been developed. ${ }^{3-5}$ However, many of these methodologies have problems when dealing with electron-rich arenes $^{2,6-10}$ and often employ expensive starting materials such as in the palladium-catalyzed method developed by Buchwald. ${ }^{11}$ In recent times other methods to introduce the $\mathrm{SCF}_{3}$ group have been developed; those include -but are not limited to- the usage of alkenes, ${ }^{12-14}$ arenes, ${ }^{15}$ alkynes, ${ }^{16-18}$ Grignard reagents ${ }^{19}$, boronic acids ${ }^{20-22}$ and diazonium salts ${ }^{23-26}$ as substrates combined with different transition metal catalysts e.g. $\mathrm{Cu}, \mathrm{Ni}$ or $\mathrm{Ag}$. In 2012 Vicic et al. reported one of the first procedures to prepare $\mathrm{Ar}-\mathrm{SCF}_{3}$ compounds in good yields from aryl iodides and bromides. This method employs a nickel catalyst along with the 4,4'-dimethoxybipyridine (dmbpy) ligand and the inexpensive $\left[\mathrm{NMe}_{4}\right]\left[\mathrm{SCF}_{3}\right]$ salt at room temperature (Scheme 2$)^{27}$

Scheme 2. Synthesis of $\mathrm{Ar}-\mathrm{SCF}_{3}$ compounds as reported by Vicic.

This methodology works best for electron-rich arenes, although some electron-poor analogues have been reported to successfully engage in the reaction. The experimental procedure provides excellent yields for aryl iodides; however, the reaction slows down when using aryl bromides and stops at all for chlorobenzene. In the original publication there was not any mechanistic insight for this coupling reaction, probably because it was assumed that it will follow the usual $\mathrm{Ni}(0) / \mathrm{Ni}(\mathrm{II})$ catalytic cycle. In a more recent publication, ${ }^{28}$ a relevant piece

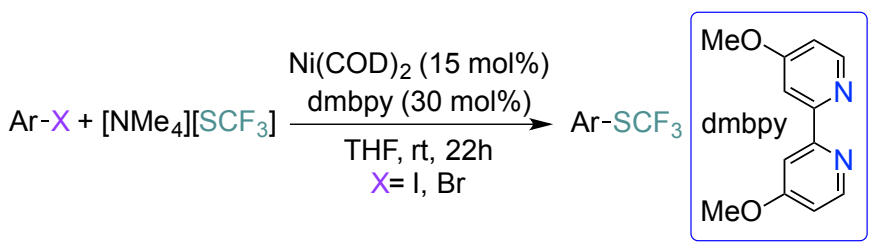


of the mechanism of this reaction, including the study of a $\mathrm{Ni}(0) / \mathrm{Ni}(\mathrm{II})$ mechanism, was computationally explored and it was proposed that the trilfuoromethylthiolation had to proceed through a $\mathrm{Ni}(\mathrm{I}) / \mathrm{Ni}(\mathrm{III})$ pathway. Nevertheless, this study is incomplete and some key points i.e. the generation of the active nickel catalyst and the substrate scope were not computationally addressed. Herein a full mechanistic proposal for the trifluoromethylthiolation of iodobenzene under Vicic's reaction conditions is presented. Once the mechanism has been established, the effect of replacing the substrate by electron-rich and electron-poor iodobenzene analogs, as well as by employing bromobenzene and chlorobenzene, will be evaluated.

\section{Computational details}

All the structures have been fully optimized in tetrahydrofuran using the Gaussian09 package ${ }^{29}$ with the B97D density functional. ${ }^{30}$ The standard 6-31G+(d) $)^{31-33}$ basis set was used for all $\mathrm{H}, \mathrm{C}, \mathrm{N}, \mathrm{F}, \mathrm{O}, \mathrm{S}$ and $\mathrm{Cl}$ atoms; the Stuttgart-Dresden basis set (SDD), ${ }^{34-35}$ along with the associated electron core potentials, was employed for $\mathrm{Ni}, \mathrm{Br}$ and I. Solvation free energies are computed with the (IEF-PCM) continuum dielectric solvation model $^{36-37}$ using the radii and non-electrostatic terms of the SMD solvation model. ${ }^{38}$ In all cases, frequency calculations were carried out to ensure the nature of stationary points and transition states and to allow the calculation of the Gibbs energy for all the species involved in the catalytic cycles at $25^{\circ} \mathrm{C}$. The computed reaction mechanisms were confirmed by calculating the intrinsic reaction coordinate (IRC) $)^{39-40}$ of all transition states, which connect the reactants and products of each reaction stage. In some cases, namely for ADTS and LDTS, the IRC procedure was not successful, and potential energy surface scans had to be carried out.

Single electron transfer (SET) barriers were calculated employing Marcus theory, ${ }^{41-42}$ with the equation:

$$
\Delta G^{\ddagger}=\frac{\left(\Delta G^{\circ}+\lambda\right)^{2}}{4 \lambda}
$$

where $\Delta G^{\circ}$ is the free energy difference between reactants and products, and $\lambda$ is the reorganization energy of the nuclei involved in the electron transfer process, including the solvent molecules. The reorganization energy was computed independently for both the nuclear $\left(\lambda_{N}\right)$ and the solvent $\left(\lambda_{s}\right)$ components as reported elsewhere. ${ }^{43-44}$ The Minimum Energy Crossing Points (MECP) between potential energy surfaces with different spin states have been located with the method developed by Harvey and coworkers. ${ }^{45}$

Additional single point calculations on the previously optimized geometries were employed to obtain improved solvated free energy values with larger basis sets. The 6$311+G^{*}$ basis set $^{33}$ was used for all H, C, N, F, O and S atoms while the aug-cc-pVTZ-PP basis set, ${ }^{46}$ including the associated electron core potential, was employed for $\mathrm{Br}$ and $\mathrm{I}$. In the case of $\mathrm{Cl}$ and $\mathrm{Ni}$ atoms, the basis set was improved to aug-ccpVTZ. ${ }^{47}$ The computed Gibbs energies have been corrected to use a standard state corresponding to species in solution with a standard concentration of $1 \mathrm{M}$. This was performed by adding an extra term to the Gaussian computed energy of each species; this correction is computed as $\mathrm{RT} \ln \left(\mathrm{C}=/ \mathrm{C}^{1 \mathrm{~atm}}\right)$, where $\mathrm{C}^{\circ}$ is the standard reference state concentration $(1 \mathrm{M})$, and $\mathrm{C}^{1 \mathrm{~atm}}$ is the concentration of an ideal gas under the standard $p=1 \mathrm{~atm}$ conditions $\left(C^{1 \mathrm{~atm}}=1 / \mathrm{V}_{\mathrm{m}}=\mathrm{P} / \mathrm{RT}=0.030 \mathrm{M}\right.$ for an ideal gas at $298.15 \mathrm{~K}$ and $1 \mathrm{~atm}$ ). Numerically, this corrective term equals to $1.9 \mathrm{kcal} \mathrm{mol}^{-1}$ per molecule at 298.15 K.

Unless otherwise stated all the reported Gibbs energy values correspond to those obtained with the large basis set in THF at $25^{\circ} \mathrm{C}$.

\section{Results and discussion}

In this section the results obtained in different mechanistic scenarios for the trifluoromethylthiolation reaction reported by Vicic will be shown. Since the experiments were carried out at room temperature the proposed mechanisms should be expected to have relatively low activation barriers, typically lower than $30 \mathrm{kcal} \mathrm{mol}^{-1}$; however, the available experimental data i.e. reaction conditions, reaction time and final yields indicate that the overall barriers should be around -or lower than $-25 \mathrm{kcal} \mathrm{mol}^{-1}$. 48

First, the classical $\mathrm{Ni}(0) / \mathrm{Ni}(\mathrm{II})$ catalytic cycle, which has been usually reported in literature, ${ }^{49-50}$ has been studied (Scheme 3). The $\left[\mathrm{Ni}(\mathrm{COD})_{2}\right] / \mathrm{dmbpy}$ ratio employed in the experiments was $1: 2$; thus, the expected starting nickel species should be [Ni(dmbpy $)_{2}$ ] (A1 in Scheme 3). Replacement of one of the dmbpy ligands with a iodobenzene generates the catalytic nickel( 0 ) species (A2). There are two possible pathways for this substitution, either associative or dissociative. In practice, the latter implies the loss of one dmbpy ligand to yield [Ni(dmbpy)]. This dissociative process requires almost $38 \mathrm{kcal}$ $\mathrm{mol}^{-1}$ and thus it can be safely discarded. In the associative pathway the substrate approaches the catalyst to bind the nickel atom through a $\pi$-interaction. The pentacoordinate $\left[\mathrm{Ni}(\mathrm{Phl})(\mathrm{dmbpy})_{2}\right]$ species was sought but not found, probably because iodobenzene is not able to coordinate onto the metal. Therefore, an associative displacement process, where the ligand dissociates as the substrate comes in, was taken into consideration as the way of getting $\mathrm{Phl}$ on the nickel atom. ${ }^{51}$ Indeed, the transition state for the ligand substitution (ADTS) has been found $13.0 \mathrm{kcal} \mathrm{mol}^{-1}$ above the separated reactants, indicating this displacement process should be relatively easy. However, this ligand dissociation process is more complex than it seems and comprises more than one step; after ADTS one of the arm of dmbpy remains attached to the nickel center and a transient $\mathrm{Ni}(0)$ intermediate is formed, the Gibbs energy of which is $4.7 \mathrm{kcal} \mathrm{mol}^{-1}$. From there the dmbpy ligand is expelled in a dissociation process that does not entail a thermodynamic barrier. This is found in a linear transit energy scan following the $\mathrm{Ni}-\mathrm{N}$ ligand dissociation coordinate. 


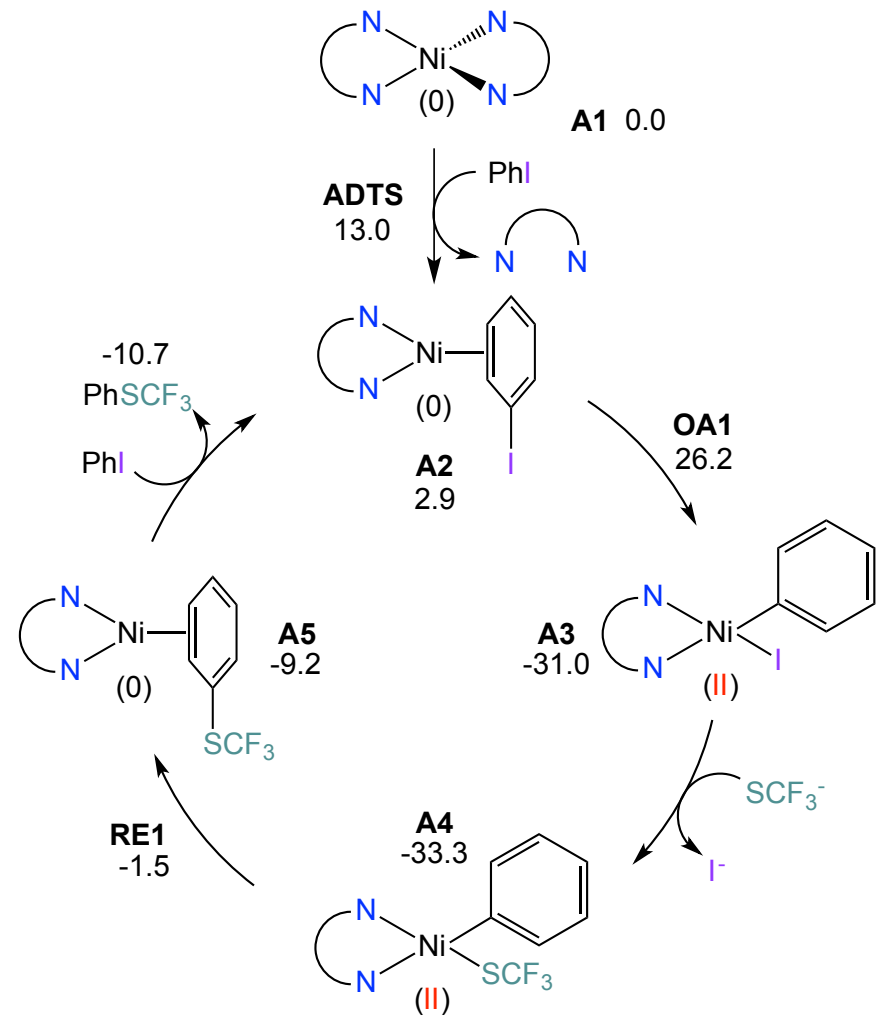

Scheme 3. $\mathrm{Ni}(0) / \mathrm{Ni}(\mathrm{II})$ catalytic cycle including Gibbs energies in $\mathrm{kcal}^{\mathrm{mol}}{ }^{-1}$ (nickel oxidation state is given between brackets).

The dmbpy ligand decoordination produces the [Ni(dmbpy)(Phl)] species (A2), which is found to be $2.9 \mathrm{kcal}$ $\mathrm{mol}^{-1}$ higher than the starting materials, and constitutes the starting point of the catalytic cycle. Once $\mathbf{A} \mathbf{2}$ has been formed the reaction should proceed by the concerted oxidative addition through OA1 to yield the nickel(II) intermediate A3, which is more than $30 \mathrm{kcal} \mathrm{mol}^{-1}$ lower in energy than the starting materials. The transition state for this process seems to be quite high, though, as it is found $23.3 \mathrm{kcal} \mathrm{mol}^{-1}$ higher than A2. Moreover, the total activation energy at this point is $26.2 \mathrm{kcal} \mathrm{mol}^{-1}$, a high enough energy barrier to significantly slow down the reaction at room temperature. Once $\mathbf{A} \mathbf{3}$ is formed the reaction should proceed by replacing the iodide with trifluoromethylsulfide $\left(\mathrm{SCF}_{3}{ }^{-}\right)$. The newly formed $\left[\mathrm{Ni}(\mathrm{Ph})\left(\mathrm{SCF}_{3}\right)(\mathrm{dmbpy})\right]$ intermediate $(\mathrm{A} 4)$ is slightly more stable than $\mathbf{A} \mathbf{3}$, and constitutes the lowest intermediate along this reaction pathway. The transition state governing the $1 / \mathrm{SCF}_{3}{ }^{-}$ replacement was sought but it could not be found; nevertheless, additional calculations show that whenever an $\mathrm{SCF}_{3}$ group is placed close enough to $\mathbf{A} \mathbf{3}$ the iodide atom is automatically released without overcoming an enthalpic energy barrier. This indicates that this replacement should have -if any- a very low energy barrier. Finally, the fluorinated product can be obtained through the reductive elimination transition state (RE1) to yield $\left[\mathrm{Ni}\left(\mathrm{PhSCF}_{3}\right)(\mathrm{dmbpy})\right]$ (A5). This elimination process has a very high energy requirement of 31.8 $\mathrm{kcal} \mathrm{mol}^{-1}$, computed as the Gibbs energy difference between A4 and RE1.

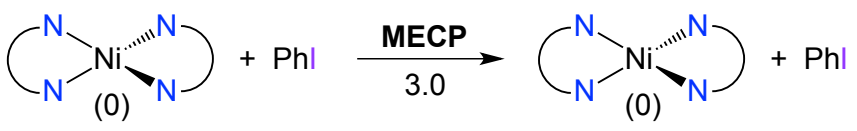

A1 0.0

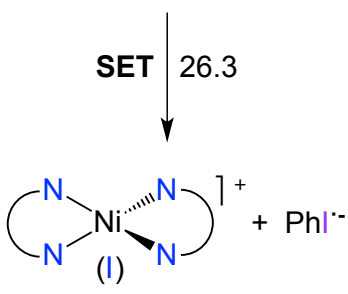

B1 1.3<smiles>NCCN[I+]1N2CCNN21</smiles>

B3 6.7

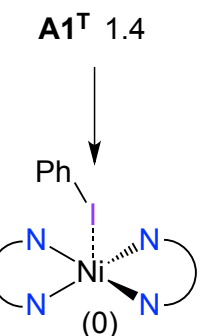

B1 $^{\top} 0.3$

HAT 3.6<smiles>[Y]C(CC)Pc1ccccc1</smiles>
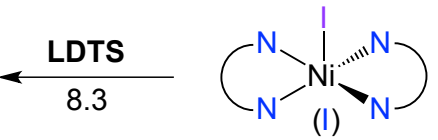

B2 -6.2
Scheme 4. $\mathrm{Ni}(\mathrm{I})$ catalyst generation from the starting materials (Gibbs energies in kcal $\mathrm{mol}^{-1}$, nickel oxidation state is given between brackets).

This large value confirms the rejection of the $\mathrm{Ni}(0) / \mathrm{Ni}(I I)$ pathway, although the overall Gibss energy for the organic transformation is exergonic by $10.7 \mathrm{kcal} \mathrm{mol}^{-1}$. These high reduction elimination barriers from $\mathrm{Ni}(\mathrm{II})$ species are very similar to those reported by Schoenebeck et al. for this same reaction, ${ }^{28}$ and have been reported previously for other similar $\mathrm{Ni}(0) / \mathrm{Ni}(\mathrm{II})$ systems. ${ }^{52-53}$ Other reductive eliminations, carried out with an extra iodide or an incoming iodobenzene close to the metal center did not improve the energies obtained for this step. Additionally, intermediate A5 is found to be well above $\mathbf{A 4}$, which adds an extra reason to discard this catalytic cycle.

Since calculations seem to rule out the classical $\mathrm{Ni}(0) / \mathrm{Ni}(\mathrm{II})$ pathway an alternative mechanism has to be found. Another possible mechanistic scenario would imply a $\mathrm{Ni}(\mathrm{I}) / \mathrm{Ni}(\mathrm{III})$ catalytic cycle; although not very usual, some catalytic processes are known to involve these species. ${ }^{28,}$, 54-57 Two different options, among all the existing possibilities, have been studied for getting a competent $\mathrm{Ni}(\mathrm{l})$ catalyst, namely [Nil(dmbpy)], from the starting materials (Scheme 4). The first pathway to reach this complex starts with an outer-sphere single electron transfer $(\mathrm{SET})^{58-62}$ between $\left[\mathrm{Ni}(\mathrm{dmbpy})_{2}\right]$ and $\mathrm{Phl}$; which should produce the corresponding $\left[\mathrm{Ni}(\mathrm{dmbpy})_{2}\right]^{+}$ (B1) and $\mathrm{Phl}$ radical anion species. Although this process is not very energetically demanding in thermodynamic terms (1.3 kcal $\mathrm{mol}^{-1}$ ), the computed energy barrier for the electron transfer (SET) seems, however, too high $\left(26.3 \mathrm{kcal} \mathrm{mol}^{-1}\right)$ to permit this process at room temperature. The second mechanistic option to get to the functional $\mathrm{Ni}(\mathrm{l})$ catalyst involves the halogen atom transfer (HAT) ${ }^{63-65}$ between the starting materials but, in this case, this transfer could only be found through the triplet state of the starting nickel(0) species 
[Ni(dmbpy $\left.)_{2}\right]$. In first instance, the iodine atom transfer possibility was studied in the singlet energy surface i.e. between species $\mathbf{A} \mathbf{1}$ and $\mathrm{Phl}$ but the corresponding transition state could not be found. Hence, the next choice was carrying out the halogen atom transfer in the triplet state. To do so, and prior to the HAT step, the $\left[\mathrm{Ni}(\mathrm{dmbpy})_{2}\right.$ ] triplet species $\left(\mathbf{A} 1^{\top}\right)$ and the minimum energy crossing point (MECP) connecting the singlet and triplet energy surfaces, i.e. A1 and $\mathbf{A 1}^{\top}$, have been computed. These 2 species are quite similar in geometry and energy; for instance, the average $\mathrm{Ni}-\mathrm{N}$ increases from 1.96 to $2.01 \AA$ when going from $\mathbf{A} \mathbf{1}$ to $\mathbf{A} \mathbf{1}^{\top}$, and the angle between both ligand planes remains practically unchanged $\left(42^{\circ}\right.$ vs. $\left.39^{\circ}\right)$. On the other hand, the energy difference between both species is $1.4 \mathrm{kcal} \mathrm{mol}^{-1}$ in favor of the closedshell species. These small differences explain the low energy requirement to transform $\mathbf{A} 1$ into $\mathbf{A 1}^{\top}$ ( $3 \mathrm{kcal} \mathrm{mol}^{-1}$ ) through MECP. This process is clearly facilitated by the bipyridine ligands, which allow the formation of the diradical species by accepting the excited electron from $\mathrm{Ni}(0)$ i.e. $\mathbf{A} 1$ should be seen as $\left[\mathrm{Ni}^{0}(\mathrm{dmbpy})_{2}\right]$ while $\mathbf{A} \mathbf{1}^{\top}$ should be $\left[\mathrm{Ni}^{-}\left((\mathrm{dmbpy})_{2}\right)^{-}\right]$. The population analysis in $\mathbf{A} \mathbf{1}^{\boldsymbol{\top}}$ reveals that one of the d-orbitals of nickel is singly occupied while the highest energy alpha orbital, which belongs mostly to the p-system of the ligands, contains the other unpaired electron. This diradical electron distribution can be observed in the spin density representation, which spreads on the metal and all along the aromatic ensemble of the complex (Figure 1). Once $\mathbf{A} \mathbf{1}^{\top}$ is formed it could interact with iodobenzene to produce intermediate $\mathbf{B} \mathbf{1}^{\top}$, also in the triplet energy surface. $\ln \mathbf{B} \mathbf{1}^{\top}$ the iodide atom directly points to the nickel atom although the distance between them is still quite large (3.42 $\AA$ ). Even so, the Gibbs energy change associated to this stage is negative by $c a$. $1 \mathrm{kcal} \mathrm{mol}^{-1}$. Then the halogen atom transfer (HAT) should take place to deliver two radical species: [ $\mathrm{Nil}\left(\mathrm{dmbpy}_{2}\right)_{2}$ (B2) plus a phenyl radical. The energy requirement for this process is as low as $3.3 \mathrm{kcal} \mathrm{mol}^{-1}$, and the species formed are more stable than the previous ones. In $\mathbf{B 2}$, the $\mathrm{Ni}-\mathrm{I}$ distance is quite long (ca. $3.7 \AA$ ) and indicates this species should better be seen as an ion pair. The approach of iodide to nickel and the release of one bipyridine ligand produces the $\mathrm{Ni}(\mathrm{I})$ active catalyst [Nil(dmbpy)] (B3). This process is not energetically favored and both the transition state (LDTS) and the final product (B3) are found above B2. Nevertheless, the energy barrier to obtain B3 is $14.5 \mathrm{kcal} \mathrm{mol}^{-1}$, and thus this species could still be taken into consideration as a plausible catalyst for the studied reaction. The nature of LDTS is similar to that of ADTS described above; after the transition state the dmbpy ligand remains attached to $\mathrm{Ni}$ by one arm, forming a transient tetracoordinate complex with a relative Gibbs energy of $0.3 \mathrm{kcal} \mathrm{mol}^{-1}$. The dmbpy ligand leaves afterwards, following a barrierless process that produces B3; again this is confirmed by a $\mathrm{Ni}-\mathrm{N}$ reaction coordinate energy scan. Of course, there should be other plausible options to get to B3; for example, $\mathrm{Ni}(\mathrm{I})$ catalysts have been shown to arise by comproportionation of coexisting $\mathrm{Ni}(0)$ and $\mathrm{Ni}(\mathrm{II})$ species under catalytic conditions. ${ }^{66-67}$ However, this is not the case for the trifluoromethylthiolation studied here.

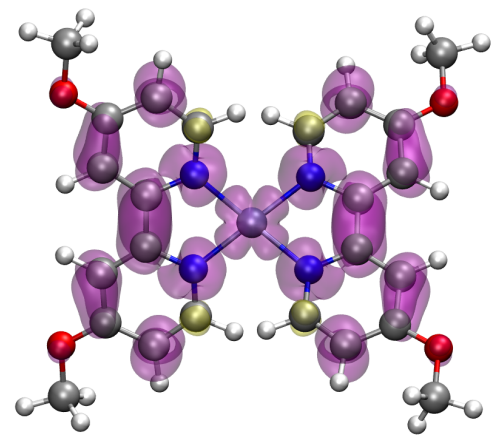

Figure 1. Spin density distribution on complex $\mathbf{A 1}^{\top}$; color code: $\mathrm{C}=$ gray, $\mathrm{N}=$ blue, $\mathrm{O}=$ red, $\mathrm{Ni}=$ iceblue, $\mathrm{H}=$ white, alpha and beta spin densities (isovalue of $10^{-3}$ a.u.) are purple and yellow, respectively.

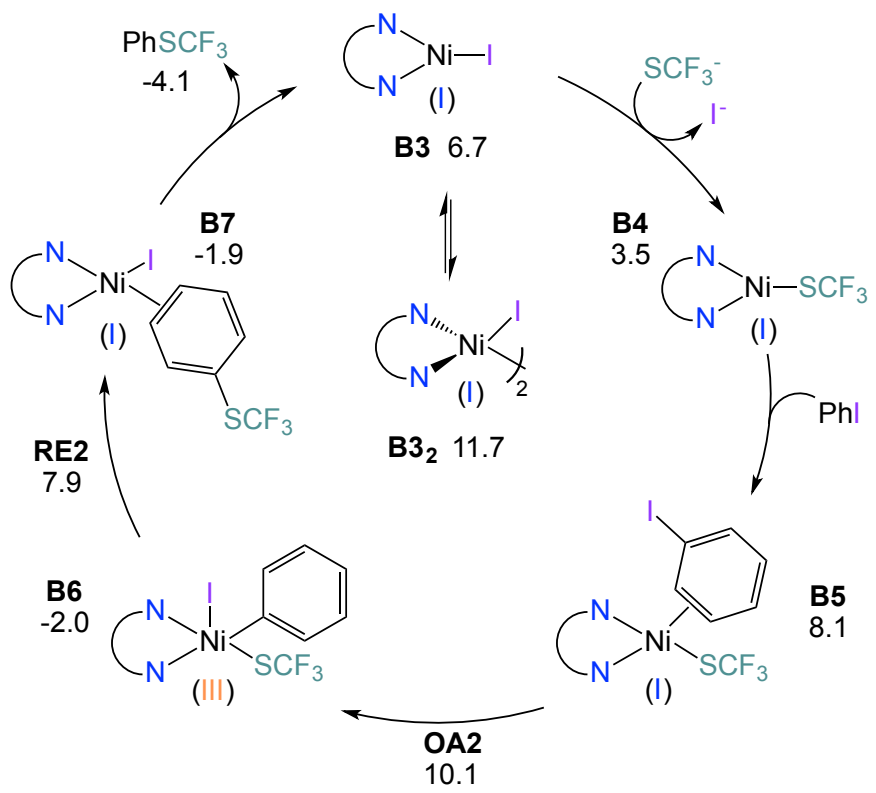

Scheme 5. $\mathrm{Ni}(\mathrm{I}) / \mathrm{Ni}(\mathrm{III})$ catalytic cycle including Gibbs energies in $\mathrm{kcal} \mathrm{mol}^{-1}$ (nickel oxidation state is given between brackets).

Species B3 should be able to -potentially- dimerize and give rise to compounds with formula $[\mathrm{LNi}(\mathrm{I})]_{2}$, which may be relevant into the catalysis manifold. Calculations on this kind of compounds show that the lowest-energy dimer $\mathbf{B}_{\mathbf{2}} \mathbf{2}_{\mathbf{2}}$ in Scheme 5) corresponds to a ferromagnetic $\mathrm{Ni}(\mathrm{I})$ dinuclear complex with bridging iodide ligands. Nevertheless, the formation of such species has an energy requirement of $5 \mathrm{kcal} \mathrm{mol}^{-1}$, indicating that the dimerization of $\mathbf{B} \mathbf{3}$ into $\mathbf{B}_{\mathbf{2}}$ is not very likely to occur under the reaction conditions. As may be observed, this precatalytic cycle produces a phenyl radical, which could attack B2, B3 or B4 to form nickel(II) complexes, which have been demonstrated to be a dead end for the overall process. However, in B2 there are still two dmbpy ligands attached onto the metal center and those would probably protect the catalytic species from that side reaction. The relative orientation of the species in the HAT transition state suggests that the phenyl radical should diffuse into the reaction mixture and interact with the solvent molecules, rather than coming back onto the nickel center. In principle, the reaction of B3 or B4 with a phenyl radical should be possible and $\mathbf{A} \mathbf{3}$ or $\mathbf{A 4}$ ) 
could be formed, thus producing dead-end species that would slow down the overall reaction. Even so, the concentration of B3/B4 and Ph. should be low enough to infer they would not meet again in solution. In addition, experiments do not account for the formation of dead-end $\mathrm{Ni}(\mathrm{II})$ species such as $\mathbf{A} \mathbf{3}$ or A4. In any case, the fate of the phenyl radical is difficult to assess and, for the sake of brevity, has not been explored.

Once the active $\mathrm{Ni}(\mathrm{l})$ species $\mathbf{B} 3$ has been obtained the reaction should proceed by following a $\mathrm{Ni}(\mathrm{I}) / \mathrm{Ni}(\mathrm{III})$ catalytic cycle that resembles the classical cross-coupling reactions (Scheme 5). The reaction goes on by replacing the iodide on $\mathbf{B} \mathbf{3}$ by a trifluoromethylsulfide group to form B4. This process is exergonic by more than $3 \mathrm{kcal} \mathrm{mol}^{-1}$ and, since the nickel center is tricoordinate, we do not expect it to have a significant energy barrier. In addition trying to reach the tetracoordinate $\left[\mathrm{Nil}\left(\mathrm{SCF}_{3}\right)(\mathrm{dmbpy})\right]^{-}$is not possible since the approach of $\mathrm{SCF}^{-}$to the nickel center entails the automatic detachment of the iodide ligand. After this replacement, a Phl substrate molecule coordinates to the free position of the metal to form B5; the Gibbs energy computed for this species is $4.6 \mathrm{kcal} \mathrm{mol}^{-1}$ higher than that found for the previous intermediate. Once the iodobenzene is coordinated the oxidative addition happens, through the corresponding concerted transition state (OA2), to yield the $\mathrm{Ni}$ (III) intermediate B6. Interestingly, the energy requirement for overcoming OA2 is only $2 \mathrm{kcal} \mathrm{mol}^{-1}$, indicating that the oxidative addition process leading to the nickel(III) species is practically barrierless. B6 adopts a square pyramid structure with the iodide occupying the axial position; this configuration leaves the trifluoromehtylsulfide and the phenyl ring in a cis arrangement, which should be appropriate to produce the final product by reductive elimination. In fact, this elimination (RE2) readily happens with an energy requirement of only 9.9 $\mathrm{kcal} \mathrm{mol}^{-1}$. Other square pyramid and trigonal bipyramidal structures such as those reported in reference 28 , which may be formed by isomerization of $\mathbf{B 6}$, have been computed and found to lie at higher energies. Alternatively, B6 could be accessed from B3 following a reverse reaction sequence, in which $\mathrm{Phl}$ is coordinated and activated by oxidative addition, and subsequently iodide is replaced by $\mathrm{SCF}_{3}{ }^{-}$. However, the oxidative addition transition state for this pathway is located at a relative Gibbs energy of $12.2 \mathrm{kcal} \mathrm{mol}^{-1}$, higher than any other species along the $\mathrm{Ni}(\mathrm{I}) / \mathrm{Ni}(\mathrm{III})$ pathway, which makes this sequence less likely to happen. The final intermediate of the catalytic cycle (B7) is the recovered nickel(I) catalyst with the newly formed product coordinated through the phenyl ring; the release of $\mathrm{PhSCF}_{3}$, takes the catalytic cycle back to the starting point (B3).

A close analysis of the Gibbs energy evolution throughout the catalytic cycle reveals that the barrier for the studied reaction corresponds to the reductive elimination process (from B6 to RE2) which accounts for $9.9 \mathrm{kcal} \mathrm{mol}^{-1}$. $^{68}$ This value is much lower than that obtained in the $\mathrm{Ni}(0) / \mathrm{Ni}(\mathrm{II})$ catalytic cycle $(31.8$ $\mathrm{kcal} \mathrm{mol}^{-1}$ ) and indicates that the reaction should follow a $\mathrm{Ni}(\mathrm{I}) / \mathrm{Ni}(\mathrm{III})$ pathway. It has to be noted that the Gibbs energy required for the first turnover, i.e. including the generation of the $\mathrm{Ni}(\mathrm{I})$ catalyst, and computed as the energy difference between $\mathbf{B 2}$ and $\mathbf{O A 2}$, is $16.3 \mathrm{kcal} \mathrm{mol}^{-1}$, slightly higher than that found in the $\mathrm{Ni}(\mathrm{I}) / \mathrm{Ni}(\mathrm{III})$ catalytic cycle shown in Scheme 5 . These values seem to be relatively low and a reaction with such a barrier should be quite fast, although the lack of experimental kinetics measurements does not allow a direct comparison. Nevertheless, the calculations reported by Schoenebeck et al. on this system, ${ }^{28}$ although with slightly different computational settings, afford very similar Gibbs energy profiles for the $\mathrm{Ni}(\mathrm{I}) / \mathrm{Ni}(\mathrm{III})$ catalytic cycle. In any case, the analysis of the computational results should not be completely focused in the results -or just one numberobtained for this particular reaction; right below the results for other substrates will be analyzed and a larger, and more complete, picture of the reaction will be obtained. With that picture at hand it will be possible to ascertain that, although the computed barrier does not seem a perfect match, it is a good approximation to the overall reactivity described in the experimental report.

Once a plausible catalytic cycle for the reaction has been determined it should be possible to analyze the effects of replacing the substrate with bromobenzene and chlorobenzene. Experimentally, it was stated that $\mathrm{PhBr}$ slows down the reaction (yield drops to 65\%) while $\mathrm{PhCl}$ does not work at all. Scheme 6 shows the Gibbs energy profiles computed for these different halobenzenes in the operative $\mathrm{Ni}(\mathrm{I}) / \mathrm{Ni}(\mathrm{III})$ catalytic cyle; Table S1 contains all the computed Gibbs energies including also the $\mathrm{Ni}(0) / \mathrm{Ni}(\mathrm{II})$ cycle. The calculations show the reasons that make chlorobenzene a very poor substrate this trifluoromethylthiolation process; first of all, and most important, the Gibbs energy change for the overall transformation is positive $\left(+4.0 \mathrm{kcal} \mathrm{mol}^{-1}\right)$ indicating this should be an endergonic reaction. And to make matters worse, the energy barriers found in the $\mathrm{Ni}(0) / \mathrm{Ni}(\mathrm{II})$ and $\mathrm{Ni}(\mathrm{I}) / \mathrm{Ni}(\mathrm{III})$ catalytic cycles are 40.6 (from A3 to RE1) and 33.9 (from $\mathbf{B 1}^{\top}$ to $\mathbf{O A 2}$ ) $\mathrm{kcal} \mathrm{mol}^{-1}$, respectively. These values, combined with the endergonicity of the overall process explain why chlorobenzene is unreactive under the experimental conditions employed. In the case of bromobenzene, the computed overall Gibbs energy indicates that the reaction is slightly exergonic $\left(-0.8 \mathrm{kcal} \mathrm{mol}^{-1}\right)$. In line with the results found for $\mathrm{Phl}$, the energy barriers found in the $\mathrm{Ni}(0) / \mathrm{Ni}(\mathrm{II})$ catalytic cycle of $\mathrm{PhBr}$ seem to be too high to allow the reaction to proceed; the oxidative addition and reductive elimination barriers are 26.3 (from A2 to OA1) and 38.6 (from A3 to RE1) kcal mol ${ }^{-1}$, respectively, which makes this reaction pathway not plausible. In contrast, the alternative $\mathrm{Ni}(\mathrm{I}) / \mathrm{Ni}(\mathrm{III})$ catalytic cycle seems to provide a reasonable answer to the reactivity shown by bromobenzene. The formation of the $\mathrm{Ni}(\mathrm{I})$ catalyst requires $11.3 \mathrm{kcal} \mathrm{mol}^{-1}$, and correspond to the bromine atom transfer (HAT) between the initial catalyst and $\mathrm{PhBr}$ in the triplet energy surface. Exploration of the $\mathrm{Ni}(\mathrm{I}) / \mathrm{Ni}(\mathrm{III})$ cycle reveals that the highest energy structure is the oxidative addition of bromobenzene (OA2) and the overall in-cycle barrier is obtained as the energy difference between this species and $\mathrm{PhBr}$ plus [ $\mathrm{NiBr}(\mathrm{dmbpy})]$ (B3), which has a value of $16 \mathrm{kcal} \mathrm{mol}^{-1}$. This value seems to be too low for a reaction that was reported to be relatively slow at room 
temperature. A plausible explanation for this could be related to the activation energy for the first turnover; in the case of $\mathrm{Phl}$ the energy required to generate the $\mathrm{Ni}(\mathrm{l})$ catalyst and afford the product is $16.3 \mathrm{kcal} \mathrm{mol}^{-1}$ while for $\mathrm{PhBr}$ this barrier (calculated as the energy difference between the starting materials and OA2) rises to $24.6 \mathrm{kcal} \mathrm{mol}^{-1}$. This value indicates that the first turnover for bromobenzene is in the operative limit for a reaction working at room temperature. Therefore, and as observed experimentally, $\mathrm{PhBr}$ should be expected to produce a slower reaction than $\mathrm{Phl}$ under the same experimental conditions, in which $\mathrm{PhCl}$ is completely unreactive.

Experimentally, it has been stated that the trifluoromethylthiolation reaction works slightly better for electron rich substrates; for instance, the yields obtained for 4iodotoluene and ethyl 4-iodobenzoate are 90 and 45\%, respectively. ${ }^{27}$ In order to rationalize these results most species have been recomputed for these two additional parasubstituted iodobenzenes, although in the case of the latter the ethyl group has been replaced by a methyl to simplify the calculations. Scheme 7 shows the Gibbs energy profiles for these substrates in the $\mathrm{Ni}(\mathrm{I}) / \mathrm{Ni}(\mathrm{III})$ catalytic cycle. The computed Gibbs energy values for these modified substrates can be found in Table S2. The $\mathrm{Ni}(0) / \mathrm{Ni}(\mathrm{II})$ catalytic cycle remains also shut down for these substituted iodobenzenes because the computed barriers are very close to $30 \mathrm{kcal} \mathrm{mol}^{-1}$ (Table S2). As may be observed, the behavior of 4-iodotoluene and methyl 4-iodobenzoate in the $\mathrm{Ni}(\mathrm{I}) / \mathrm{Ni}(\mathrm{III})$ catalytic cycle is very similar to that of iodobenzene. In both cases the first turnover barrier is computed as the energy difference between $\mathbf{B 2}$ and the oxidative addition transition state (OA2). The in-cycle barrier shows also the same pattern, and the barrier is computed as the energy difference between B6 and the reductive elimination transition state (RE2). In the case of 4-iodotoluene the first turnover and in-cycle Gibbs energy barriers are 18.3 and $10.2 \mathrm{kcal} \mathrm{mol}^{-1}$, respectively. On the other hand, the barriers for methyl 4-iodobenzoate are 19.0 and $10.3 \mathrm{kcal} \mathrm{mol}^{-1}$. Again, these values seem too low to quantitatively explain the experimental results. However, the small differences in the computed barriers could explain the relatively low yield variation; a $90 \%$ vs. $45 \%$ yield difference under the experimental conditions corresponds to an energy difference of ca. $0.3 \mathrm{kcal} \mathrm{mol}^{-1}$, well within the errors expected in DFT calculations. Overall, the first turnover and in-cycle barriers computed for iodobenzene (16.3 and $9.9 \mathrm{kcal} \mathrm{mol}^{-1}$ ) are lower than those found for 4-iodotoluene and methyl 4iodobenzoate, therefore explaining why the former is a bit faster to react and justifying the experimental yields of 96,90 and $45 \%$, respectively.

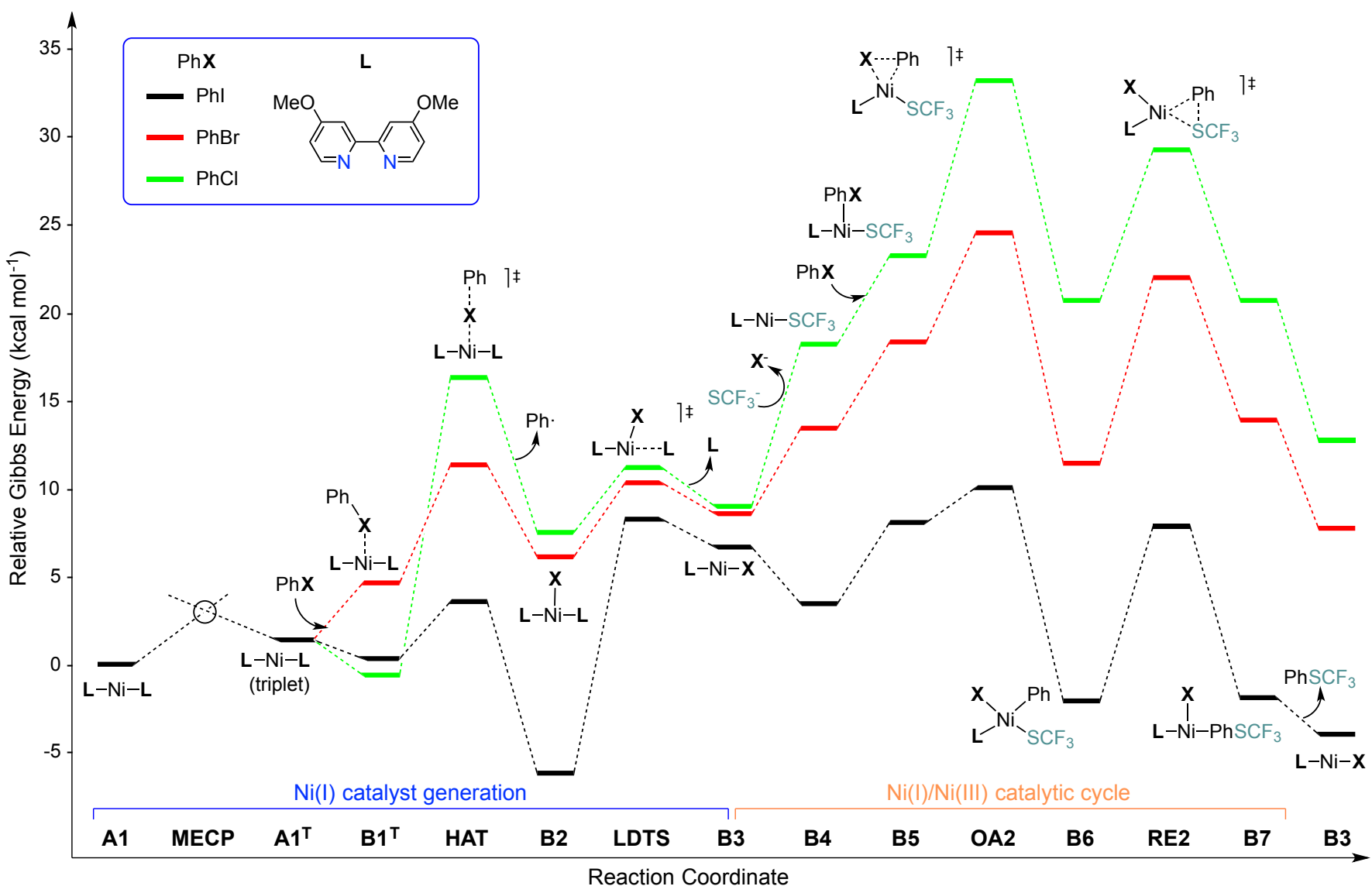

Scheme 6. Computed Gibbs energies ( $\mathrm{kcal} \mathrm{mol}^{-1}$ ) in the $\mathrm{Ni}(\mathrm{I}) / \mathrm{Ni}(\mathrm{III})$ trifluoromethylthiolation of iodobenzene (black), bromobenzene (red) and chlorobenzene (green). 


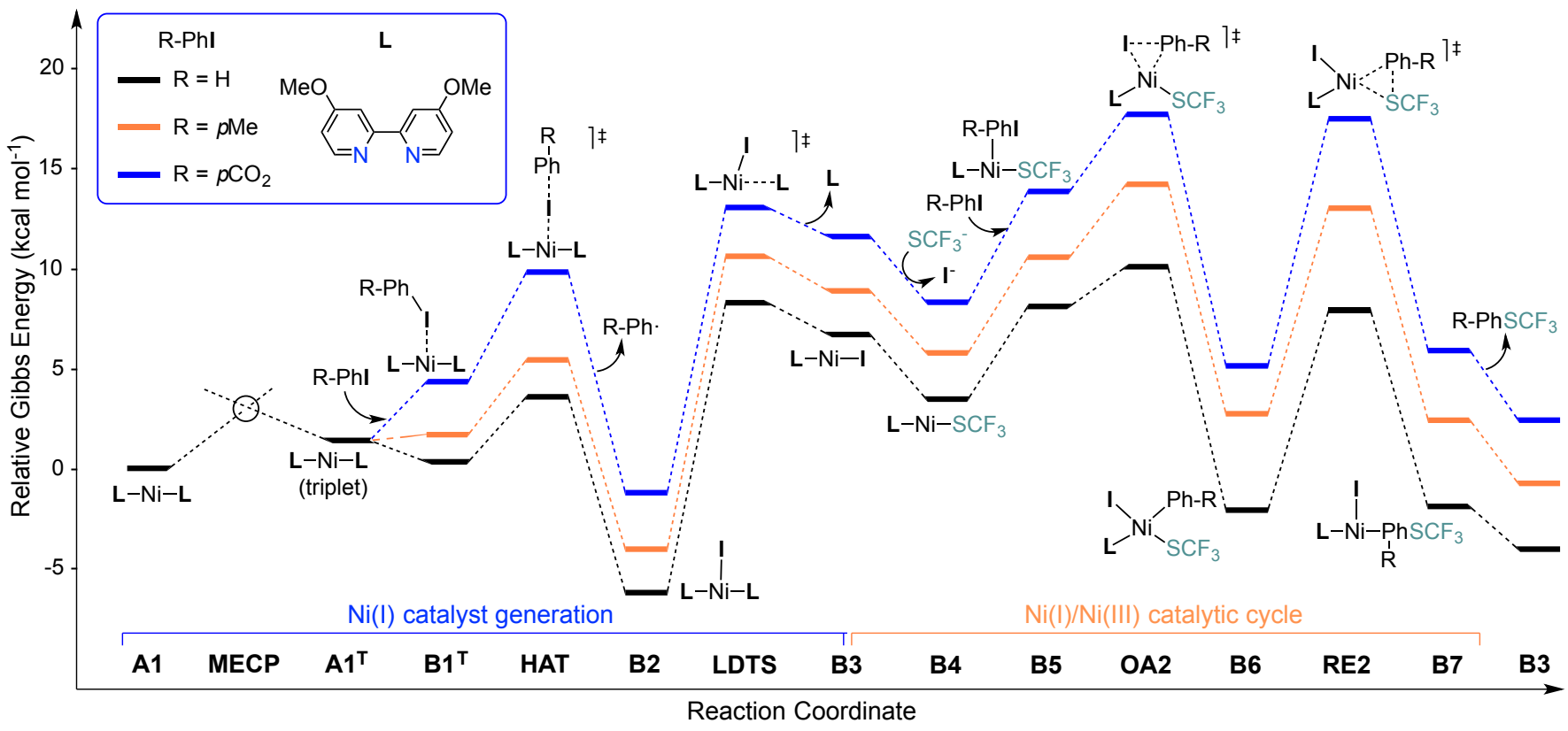

Scheme 7. Computed Gibbs energies ( $\mathrm{kcal} \mathrm{mol}^{-1}$ ) in the $\mathrm{Ni}(\mathrm{I}) / \mathrm{Ni}(\mathrm{III})$ trifluoromethylthiolation of iodobenzene (black), 4-iodotoluene (orange) and methyl 4-iodobenzoate (blue).

\section{Conclusions}

A plausible full mechanism has been proposed for the nickelcatalyzed synthesis of aryl trifluoromethyl sulfides developed by Vicic et al. At first, the reaction was expected to follow the usual $\mathrm{Ni}(0) / \mathrm{Ni}(\mathrm{II})$ pathway but this was soon discarded due to the high barriers found, close to or over $30 \mathrm{kcal} \mathrm{mol}^{-1}$, which are not suitable for a reaction working at room temperature. Instead, a catalytic cycle that follows a $\mathrm{Ni}(\mathrm{I}) / \mathrm{Ni}(\mathrm{III})$ sequence provided a better description of the reaction; the active catalyst is a $\mathrm{Ni}(\mathrm{I})$ tricoordinate complex that allows a fast oxidative addition of $\mathrm{Phl}$ and an easy coordinate reductive elimination of the product. The barriers found for the reaction are quite low, in agreement with the reaction working at room temperature.

The proposed mechanism is also able to explain the behavior of other halobenzenes under the same reaction conditions. For $\mathrm{PhBr}$ the barriers found are higher than for $\mathrm{Phl}$, including a barrier for the first turnover of $24.6 \mathrm{kcal} \mathrm{mol}^{-1}$, which is close to the limit for a reaction working at room temperature. In the case of $\mathrm{PhCl}$ it has been found that the overall Gibbs energy for the reaction is endergonic, and the barriers computed in the catalytic cycle are also too large for allowing the reaction. The studied mechanisms allow also interpreting the relative reaction rates for the electron rich (4-iodotoluene) and poor (methyl 4-iodobenzoate) substrates. Both compounds follow the $\mathrm{Ni}(\mathrm{I}) / \mathrm{Ni}(\mathrm{III})$ pathway and the computed energy barriers are quite close, although the former has slightly lower energy requirements and thus produces a faster reaction.

\section{Conflicts of interest}

There are no conflicts to declare.

\section{Acknowledgements}

Financial support from MINECO PGC2018-093863-B-C21 and Spanish Structures of Excellence María de Maeztu program through grant MDM-2017-0767 is fully acknowledged.

\section{Notes and references}

1 C. Hansch and A. Leo, Substituent constants for correlation analysis in chemistry and biology, Wiley, New York, 1979.

2 V. N. Boiko, Beilstein J. Org. Chem., 2010, 6, 880-921.

3 A. Tlili and T. Billard, Angew. Chem. Int. Ed., 2013, 52, 68186819.

4 X.-H. Xu, K. Matsuzaki and N. Shibata, Chem. Rev., 2015, 115, 731-764.

5 M. Hamzehloo, A. Hosseinian, S. Ebrahimiasl, A. Monfared and E. Vessally, J. Fluorine Chem., 2019, 224, 52-60.

6 Q.-Y. Chen and J.-X. Duan, J. Chem. Soc. Chem. Comm., 1993, 918-919.

7 T. Billard, S. Large and B. R. Langlois, Tetrahedron Lett., 1997, 38, 65-68.

8 S. J. Tavener, D. J. Adams and J. H. Clark, J. Fluorine Chem., 1999, 95, 171-176.

9 D. J. Adams and J. H. Clark, J. Org. Chem., 2000, 65, 14561460.

10 D. J. Adams, A. Goddard, J. H. Clark and D. J. Macquarrie, Chem. Comm., 2000, 987-988.

11 G. Teverovskiy, D. S. Surry and S. L. Buchwald, Angew. Chem. Int. Ed., 2011, 50, 7312-7314.

12 K. Zhang, J.-B. Liu and F.-L. Qing, Chem. Comm., 2014, 50 , 14157-14160.

13 K. Guo, H. Zhang, S. Cao, C. Gu, H. Zhou, J. Li and Y. Zhu, Org. Lett., 2018, 20, 2261-2264.

14 P. Saravanan and P. Anbarasan, Chem. Comm., 2019, 55, 4639-4642.

15 X.-G. Liu, Q. Li and H. Wang, Adv. Synth. Catal., 2017, 359, $1942-1946$.

16 S. Alazet, L. Zimmer and T. Billard, Angew. Chem. Int. Ed., 2013, 52, 10814-10817. 
17 R. Pluta, P. Nikolaienko and M. Rueping, Angew. Chem. Int Ed., 2014, 53, 1650-1653.

18 A. Tlili, S. Alazet, Q. Glenadel and T. Billard Chem. Eur. J., 2016, 22, 10230-10234.

19 F. Baert, J. Colomb and T. Billard, Angew. Chem. Int. Ed., 2012, 51, 10382-10385.

20 C. Chen, Y. Xie, L. Chu, R.-W. Wang, X. Zhang and F.-L. Qing, Angew. Chem. Int. Ed., 2012, 51, 2492-2495.

21 C.-P. Zhang and D. A. Vicic, Chem. Asian J., 2012, 7, 17561758.

22 X. Shao, X. Wang, T. Yang, L. Lu and Q. Shen, Angew. Chem. Int. Ed., 2013, 125, 3541-3544.

23 G. Danoun, B. Bayarmagnai, M. F. Gruenberg and L. J. Goossen, Chem. Sci., 2014, 5, 1312-1316.

24 Q. Lefebvre, E. Fava, P. Nikolaienko and M. Rueping, Chem. Comm., 2014, 50, 6617-6619.

25 C. Matheis, T. Krause, V. Bragoni and L. J. Goossen, Chem. Eur. J., 2016, 22, 12270-12273.

26 M. Lübcke, D. Bezhan and K. J. Szabó, Chem. Sci., 2019, 10, 5990-5995.

27 C.-P. Zhang and D. A. Vicic, J. Am. Chem. Soc., 2012, 134, 183185.

28 I. Kalvet, Q. Guo, G. J. Tizzard and F. Schoenebeck, ACS Catal., 2017, 7, 2126-2132.

29 M. J. Frisch, G. W. Trucks, H. B. Schlegel, G. E. Scuseria, M. A. Robb, J. R. Cheeseman, G. Scalmani, V. Barone, B. Mennucci, G. A. Petersson, H. Nakatsuji, M. Caricato, X. Li, H. P. Hratchian, A. F. Izmaylov, J. Bloino, G. Zheng, J. L. Sonnenberg, M. Hada, M. Ehara, K. Toyota, R. Fukuda, J. Hasegawa, M. Ishida, T. Nakajima, Y. Honda, O. Kitao, H. Nakai, T. Vreven, J. Montgomery, J. A., J. E. Peralta, F. Ogliaro, M. Bearpark, J. J. Heyd, E. Brothers, K. N. Kudin, V. N. Staroverov, R. Kobayashi, J. Normand, K. Raghavachari, A. Rendell, J. C. Burant, S. S. Iyengar, J. Tomasi, M. Cossi, N. Rega, N. J. Millam, M. Klene, J. E. Knox, J. B. Cross, V. Bakken, C. Adamo, J. Jaramillo, R. Gomperts, R. E. Stratmann, O. Yazyev, A. J. Austin, R. Cammi, C. Pomelli, J. W. Ochterski, R. L. Martin, K. Morokuma, V. G. Zakrzewski, G. A. Voth, P. Salvador, J. J. Dannenberg, S. Dapprich, A. D. Daniels, Ö. Farkas, J. B. Foresman, J. V. Ortiz, J. Cioslowski and D. J. Fox Gaussian09, Revision D.01, Gaussian, Inc.: Wallingford CT, 2009.

30 S. Grimme, J. Comp. Chem., 2006, 27, 1787-1799.

31 P. C. Hariharan and J. A. Pople, Theor. Chem. Acc., 1973, 28, 213-222.

32 T. Clark, J. Chandrasekhar, G. W. Spitznagel and P. V. R. Schleyer, J. Comp. Chem., 1983, 294-301.

33 M. J. Frisch, J. A. Pople and J. S. Binkley, J. Chem. Phys., 1984, 80, 3265-3269.

34 T. H. Dunning and P. J. Hay, in Modern Theoretical Chemistry, ed. H. F. Schaefer III, Plenum, New York, 1976, vol. 3, pp. 128.

35 A. Bergner, M. Dolg, W. Küchle, H. Stoll and H. Preuss, Mol. Phys., 1993, 80, 1431 - 1441.

36 D. J. Tannor, B. Marten, R. Murphy, R. A. Friesner, D. Sitkoff, A. Nicholls, B. Honig, M. Ringnalda and W. A. Goddard, J. Am. Chem. Soc., 1994, 116, 11875-11882.

37 B. Marten, K. Kim, C. Cortis, R. A. Friesner, R. B. Murphy, M. N. Ringnalda, D. Sitkoff and B. Honig, J. Phys. Chem., 1996, 100, 11775-11788.

38 A. V. Marenich, C. J. Cramer and D. G. Truhlar, J. Phys. Chem. $B, 2009,113,6378-6396$.

39 K. Fukui, Acc. Chem. Res., 1981, 14, 363-368.

40 H. P. Hratchian and H. B. Schlegel, in Theory and Applications of Computational Chemistry: The First 40 Years, ed. G. F. C. E. Dykstra, K. S. Kim, and G. Scuseria, Elsevier, Amsterdam, 2005, pp. 195-249.

41 R. A. Marcus, J. Chem. Phys., 1956, 24, 966-978.
42 R. A. Marcus, Angew. Chem. Int. Ed., 1993, 32, 1111-1121.

43 D. Moia, V. Vaissier, I. López-Duarte, T. Torres, M. K. Nazeeruddin, B. C. O'Regan, J. Nelson and P. R. F. Barnes, Chem. Sci., 2014, 5, 281-290.

44 V. M. Fernandez-Alvarez and F. Maseras, Org. Biomol. Chem., 2017, 15, 8641-8647.

45 J. N. Harvey, M. Aschi, H. Schwarz and W. Koch, Theor. Chem. Acc., 1998, 99, 95-99.

46 K. A. Peterson and C. Puzzarini, Theor. Chem. Acc., 2005, 114, 283-296.

47 N. B. Balabanov and K. A. Peterson, J. Chem. Phys., 2005, 123, 064107-064115.

48 Assuming that the reaction was stoichiometric $(\mathrm{A} \rightarrow \mathrm{B})$ and first order, which should be the case producing the fastest rate law, a barrier of $25 \mathrm{kcal} \mathrm{mol}^{-1}$ at $25^{\circ}$ will have a rate constant of $2.929 \mathrm{E}-6 \mathrm{~s}^{-1}$. This rate constant, under the experimental conditions applied in the original trifluoromethylthiolation report for $\mathrm{Phl}\left(25^{\circ} \mathrm{C}, 22 \mathrm{~h}\right)$, would produce only a $20 \%$ yield, quite far from what it is observed. Of course, a barrier between 25-30 kcal mol ${ }^{-1}$ could be operative, but it would be very slow and should not be able to reproduce the experimental data. In addition, the reaction described herein has, probably, a more complex rate law and higher reactions orders, which should produce even slower reactions.

49 A. Arévalo and J. J. García, Eur. J. Inorg. Chem., 2010, 40634074.

50 X. Hu, Chem. Sci., 2011, 2, 1867-1886.

51 C. L. McMullin, J. Jover, J. N. Harvey and N. Fey, Dalton Trans., 2010, 39, 10833-10836.

52 G. G. Dubinina, W. W. Brennessel, J. L. Miller and D. A. Vicic, Organometallics, 2008, 27, 3933-3938.

53 J. Jover, F. M. Miloserdov, J. Benet-Buchholz, V. V. Grushin and F. Maseras, Organometallics, 2014, 33, 6531-6543.

54 G. D. Jones, J. L. Martin, C. McFarland, O. R. Allen, R. E. Hall, A. D. Haley, R. J. Brandon, T. Konovalova, P. J. Desrochers, P. Pulay and D. A. Vicic, J. Am. Chem. Soc., 2006, 128, 1317513183.

55 O. Vechorkin, Z. Csok, R. Scopelliti and X. Hu, Chem. Eur. J., 2009, 15, 3889-3899.

56 J. Cornella, E. Gómez-Bengoa and R. Martin, J. Am. Chem. Soc., 2013, 135, 1997-2009.

57 O. Gutierrez, J. C. Tellis, D. N. Primer, G. A. Molander and M. C. Kozlowski, J. Am. Chem. Soc., 2015, 137, 4896-4899.

58 T. J. Anderson, G. D. Jones and D. A. Vicic, J. Am. Chem. Soc., 2004, 126, 8100-8101.

59 D. A. Powell and G. C. Fu, J. Am. Chem. Soc., 2004, 126, 77887789.

60 D. A. Powell, T. Maki and G. C. Fu, J. Am. Chem. Soc., 2004, 127, 510-511.

61 J. Zhou and G. C. Fu, J. Am. Chem. Soc., 2004, 126, 13401341.

62 V. B. Phapale, E. Buñuel, M. García-Iglesias and D. J. Cárdenas, Angew. Chem. Int. Ed., 2007, 46, 8790-8795.

63 H. Matsubara, I. Ryu and C. H. Schiesser, Org. Biomol. Chem., 2007, 5, 3320-3324.

64 G. O. Jones, P. Liu, K. N. Houk and S. L. Buchwald, J. Am. Chem. Soc., 2010, 132, 6205-6213.

65 S. Zhang, Z. Zhu and Y. Ding, Dalton Trans., 2012, 41, 1383213840.

66 A. B. Dürr, H. C. Fisher, I. Kalvet, K.-N. Truong and F. Schoenebeck, Angew. Chem. Int. Ed., 2017, 56, 13431-13435.

67 M. Mohadjer Beromi, A. Nova, D. Balcells, A. M. Brasacchio, G. W. Brudvig, L. M. Guard, N. Hazari and D. J. Vinyard, J. Am. Chem. Soc., 2017, 139, 922-936.

68 S. Kozuch and S. Shaik, Acc. Chem. Res., 2010, 44, 101-110. 